\title{
Recent advances in congenital heart disease genomics
}

\section{[version 1; peer review: 2 approved]}

\section{Anna Wilsdon ${ }^{1}$, Alejandro Sifrim², Marc-Phillip Hitz², Matthew Hurles², J. David Brook ${ }^{1}$}

${ }^{1}$ School of Life Sciences, University of Nottingham, University Park, Nottingham, NG7 2RD, UK

${ }^{2}$ Wellcome Trust Sanger Institute, Hinxton, Cambridge, CB10 1SA, UK

V1 First published: 12 Jun 2017, 6(F1000 Faculty Rev):869

https://doi.org/10.12688/f1000research.10113.1

Latest published: 12 Jun 2017, 6(F1000 Faculty Rev):869

https://doi.org/10.12688/f1000research.10113.1

\section{Abstract}

Congenital heart disease is the most common congenital abnormality, and advances in medical care mean that this population of individuals is surviving for longer than ever before. It represents a significant healthcare challenge, as many patients require life-long care and individuals may ask about the likelihood of their children being affected. Whilst a number of genes have been identified previously from investigation of families with Mendelian inheritance patterns, sequencing the DNA from large cohorts of individuals with congenital heart disease is now providing fresh insights into the genetics of these conditions. This research has enabled novel gene discovery and uncovered the different genetic mechanisms underlying both isolated congenital heart disease and that which occurs in association with other medical problems. This article discusses the most recent advances in this field and the implications for patient care. In addition, we consider the challenges facing researchers in this field and emphasise the need for close working relationships between clinicians and researchers.

\section{Keywords}

congenital heart disease, genomics, de novo mutations

\section{Open Peer Review}

Approval Status

1

2

version 1

12 Jun 2017

Faculty Reviews are review articles written by the prestigious Members of Faculty Opinions. The articles are commissioned and peer reviewed before publication to ensure that the final, published version is comprehensive and accessible. The reviewers who approved the final version are listed with their names and affiliations.

\section{Silke R. Sperling, Charité-}

Universitätsmedizin Berlin, Berlin, Germany

2. Maria Grazia Andreassi, Italian National

Research Council (CNR), Pisa, Italy

Any comments on the article can be found at the end of the article. 
Corresponding author: J. David Brook (david.brook@nottingham.ac.uk)

Competing interests: The authors declare that they have no competing interests.

Grant information: JDB and AW are supported by the British Heart Foundation. AS, MH and M-PH are supported by the Wellcome Trust. The funders had no role in study design, data collection and analysis, decision to publish, or preparation of the manuscript.

Copyright: @ 2017 Wilsdon A et al. This is an open access article distributed under the terms of the Creative Commons Attribution License, which permits unrestricted use, distribution, and reproduction in any medium, provided the original work is properly cited.

How to cite this article: Wilsdon A, Sifrim A, Hitz MP et al. Recent advances in congenital heart disease genomics [version 1; peer review: 2 approved] F1000Research 2017, 6(F1000 Faculty Rev):869 https://doi.org/10.12688/f1000research.10113.1

First published: 12 Jun 2017, 6(F1000 Faculty Rev):869 https://doi.org/10.12688/f1000research.10113.1 
Congenital heart disease (CHD) is a structural abnormality in the heart that is present at birth. This can range from a simple "hole in the heart" (septal defect) that might not need any treatment to more severe abnormalities that require surgery soon after birth or within the first year of life. It affects around nine in every 1,000 babies born in the UK. Advances in surgical and medical treatments mean that individuals with CHD are surviving for longer and represent an expanding population with specific health needs. Many require life-long care because of the risk of developing primary and secondary complications of the heart valves, as well as arrhythmias, heart failure, and stroke ${ }^{1-4}$. They may also ask about the chance of any children they have being similarly affected.

Despite the fact that CHD usually occurs as a "one off" in a family, for a long while we have known that there is a genetic component, and more than 50 genes have been implicated so far ${ }^{5}$. De novo mutations leading to reduced reproductive fitness were suspected owing to the sporadic nature of CHD. At the moment, we can identify a genetic cause in around $10-20 \%$ of people with CHD; this is much more likely in those who have CHD in combination with other medical issues, including neurodevelopmental disorders. Studies have already begun to look at the potential gains of genetic evaluation in certain clinical populations including neurodevelopmental clinics and cardiology units ${ }^{6,7}$.

In this article, we will discuss the recent advances in genomics in CHD and the challenges researchers are now facing. We will also consider how findings can be translated into improved clinical care for patients.

Traditionally, the discovery of novel human disease genes has employed analysis of pedigrees with a Mendelian family history of CHD and subsequent targeted testing in others with the same phenotype. Pitfalls of this approach included difficulty ascertaining the actual incidence of CHD, understanding the full phenotypic spectrum of a mutant gene, and the possibility of erroneously ascribing blame to a variant when other diagnoses are not considered. Furthermore, follow up functional studies to help validate pathogenicity were not always carried out. Several studies also used candidate gene approaches, testing cardiac developmental genes (mainly identified in mouse models) in human cohorts with similar CHD phenotypes. However, in some cases, at least, this produced misleading genotype-phenotype associations.

More recently, a different approach has been used. Over the last few years, three studies have employed whole exome sequencing (WES) in large cohorts of people with CHD to discover novel genes. Zaidi et al. ${ }^{8}$ performed WES in 362 trios, in which the index had severe CHD, no known genetic diagnosis, and no family history of CHD. Results were compared to trios of parents and unaffected siblings from families with autism collected separately. Their analysis focussed on 4,169 genes with human orthologues that were in the top quartile for expression in an E14.5 mouse heart identified using RNA sequencing, called the high heart expression (HHE) gene group.

The authors found a significant excess of de novo protein-altering mutations in the HHE genes in individuals with CHD compared to controls. There was no significant difference between mutation load in genes seen in the lower quartile of heart expression and no increased burden in the CHD cohort compared to controls. Zaidi et al. identified eight mutations in the CHD cohort in genes that have a role in histone modification. Specifically, they were involved in production, removal, or reading of methylation of H3K4me (histone H3, lysine 4). This pathway already has links with CHD, as it includes MLL2 (Kabuki syndrome), KDM6A (X-linked Kabuki syndrome), and CHD7 (CHARGE syndrome). Other already established syndromes causing CHD result from abnormalities in histone modification, such as Rubinstein-Taybi syndrome ${ }^{9}$. This H3K4me pathway was the only gene set that was significantly enriched in the CHD cohort, and there were no mutations in these genes in the control population.

Other genes of note included WDR5, KDM5A, KDM5B, RNF20, $U B E 2 B$, components of the H2BK120 ubiquitination complex, and USP44. SMAD2 also demonstrated more mutations expected than by chance, as did SUV420H1, MED20, HUWE1, CUL3, NUB1, and NAA15. Both individuals with SMAD2 mutations had dextrocardia, which is in keeping with a known involvement in left-right organisation ${ }^{10}$. Overall, Zaidi et al. concluded that de novo proteindamaging mutations in hundreds of genes contributed to around $10 \%$ of severe CHD and that histone-modifying genes were significantly involved.

Following on from this initial study, Homsy et al. ${ }^{11}$ examined 1,213 CHD trios without a recognisable genetic diagnosis, which included the 353 trios published by Zaidi et al. ${ }^{8}$. They compared the number of de novo mutations in the CHD trios with 900 healthy trios. A significant enrichment (1.4-fold) of de novo predicted deleterious lossof-function and missense variants was found in the CHD cohort as a whole. All phenotype groups except heterotaxy displayed this trend. In addition, there was a 2.4-fold increase in deleterious mutations in the top $25 \%$ of genes expressed during heart development, the HHE list created by Zaidi et al. ${ }^{8}$. This was not seen in controls and supports the conclusions of Zaidi et al. that CHD often results from de novo mutations.

Homsy et al. also went on to consider the difference between syndromic and non-syndromic CHD (S-CHD and NS-CHD, respectively). This is an important distinction to make, as approximately 90\% of people with CHD are non-syndromic and thus have isolated CHD. S-CHD is used to describe individuals with CHD and other congenital abnormalities and/or developmental delay. They identified significant enrichment of de novo predicted damaging mutations in S-CHD where both other non-cardiac congenital abnormalities and neurodevelopmental disability were present. This was highest in the HHE genes. They did not demonstrate any significant enrichment in the NS-CHD group, so the genetic mechanism underlying this phenotype remained unknown.

Homsy et al. estimated that de novo mutations in these HHE genes contributed to CHD in $20 \%$ of individuals with CHD, neurodevelopmental disorder, and congenital abnormalities, $10 \%$ of CHD with neurodevelopmental disorder, $6 \%$ of CHD with congenital abnormalities, and only $2 \%$ of NS-CHD. The authors suggested that reduced penetrance in the same genes could lead to both S-CHD and 
NS-CHD. They noted that a number of these genes are expressed in the developing heart and brain, suggesting a shared underlying genetic aetiology of CHD and neurodevelopmental disability.

To explore the possibility that certain genes appear to be important in the brain as well as in the heart, Homsy et al. went on to consider whether there was much overlap between genes with de novo damaging mutations in their $\mathrm{CHD}$ with neurodevelopmental disorders cohort, and 1,161 genes were identified with damaging de novo mutations in a population with neurodevelopmental disability without CHD. A total of 69 genes were shared between the two cohorts and were significantly enriched for de novo damaging mutations (2.6-fold enrichment). A number of these genes are important in cardiac development pathways, including the WNT and NOTCH pathways, and the group also included transcriptional regulators and chromatin modification genes. This led the authors to suggest that there is a common aetiology for both $\mathrm{CHD}$ and neurodevelopmental disorders with variable expressivity of these genes.

Homsy et al. also compiled a list of 21 genes with multiple damaging de novo mutations in the CHD cohort only, and not controls. These genes are likely to contribute to the pathogenesis of CHD, as this increased frequency of damaging mutations is unlikely to have occurred by chance. A number of genes already known to cause CHD were identified, such as PTPN11 (Noonan syndrome), KMT2D (MLL2 Kabuki syndrome), MYH6 (atrial septal defects, cardiomyopathy), JAG1 (Alagille syndrome), CHD7 (CHARGE syndrome), ZEB2 (Mowat Wilson syndrome), and NOTCH1 (aortic valve disease and Adams Oliver syndrome). RBFOX2 was a novel gene. Three individuals from this study and an additional patient with a deletion of $R B F O X 2^{12}$ had hypoplastic left heart syndrome. The authors suggest that, as this gene is needed for the correct development of the zebrafish heart ${ }^{13}$ and is involved in epithelial-to-mesenchymal transformation, which is linked to HLHS $^{14,15}$, it is likely to be a true CHD-causing gene. Genes with the Gene Ontology terms anatomic structure morphogenesis, cardiovascular system development, neurodevelopmental abnormality, and chromatin modification were also enriched in the CHD cohort. Chromatin modification was also highlighted in line with the results of Zaidi et al. ${ }^{8}$, and these genes were still significant when the Zaidi cohort was removed from the analysis.

Thus, the genetic mechanisms behind the largest group with CHD, the NS-CHD group, remained unknown. We explored this as part of our recent worldwide collaboration with the Deciphering Developmental Disorders study and other researchers ${ }^{16}$, which identified further novel CHD genes and uncovered a role for inherited mutations in NS-CHD. This is the largest CHD WES study to date and involved 1,891 probands with S-CHD and NS-CHD.

A significant excess of de novo protein-truncating variants (PTVs) and missense variants in genes already known to cause human autosomal dominant CHD in the S-CHD group was observed. The burden of de novo PTVs in these same genes was lower in the NS-CHD group, which supports the findings of Homsy et al. and the role of de novo mutations in $\mathrm{S}-\mathrm{CHD}^{11}$. A significant excess of de novo PTVs in the S-CHD cohort in genes known to cause developmental disability (DD) but not previously linked with CHD was also reported. This expands the phenotypes associated with these genes to include CHD and supports the theory that certain genes may be important in both the heart and the brain. The work also points to further novel genes to be discovered, as there was a significant exome-wide excess of de novo missense mutations in all other remaining protein-coding genes across both NS-CHD and S-CHD groups.

The role of inherited mutations was also considered. The burden of rare inherited variants between those with $\mathrm{CHD}$ and 12,031 population-matched controls was compared. In the NS-CHD group, there was a significant excess of rare inherited PTVs in genes known to cause autosomal dominant CHD. This excess was not present in the S-CHD group. This is a novel finding, suggesting a role for inherited mutations with reduced penetrance in NS-CHD. The variants were in genes known to cause NS-CHD or S-CHD where the phenotype can be mild and hard to detect (ABCC9, ACTC1, COL1A1, NOTCH1, and NOTCH2, for example). This explains why mutations in genes known to cause S-CHD might be detected in a NSCHD population. In addition, the de novo mutations in the S-CHD group and the inherited mutations in the NS-CHD group were in different genes with no overlap. This suggests that there are other novel genes that cause NS-CHD and exhibit incomplete penetrance still to be discovered because there was an exome-wide excess of rare inherited PTVs in the remaining protein-coding genes not known previously to be associated with CHD or DD. This was not seen in the S-CHD group.

Three novel S-CHD genes-CDK13, CHD4, and PRKD1-were also identified. Mutations in $C D K 13$ were clustered together in the serine/threonine protein kinase domain. Affected individuals have recognisable facial similarities. In addition, they all have septal defects and abnormalities of the pulmonary valve. It has been shown that the complex between $C D K 13$ and cyclin $\mathrm{K}$ phosphorylates RNA polymerase II and is needed for alternative RNA splicing ${ }^{17,18}$. CHD4 is involved in chromatin remodelling as part of the NuRD complex. A mouse model has been produced without endothelial $C h d 4$, which results in death at mid-gestation due to vascular rupture $^{19}$. There are similarities in the individuals' facial features and phenotype, including developmental delay, genitourinary abnormalities, and structural brain abnormalities, which exhibits some overlap with CHARGE syndrome (CHD7). Individuals with mutations in PRKDI exhibited CHD with developmental delay as well as ectodermal and limb features. PRKD1 is a serine/threonine protein kinase that has been implicated in cardiac hypertrophy, and a conditional mouse model with a cardiac-specific Prkdl null allele results in reduced fibrosis and hypertrophy and improved cardiac function under pressure overload ${ }^{20}$. A family with truncus arteriosus and recessive PTVs in PRKDI has already been reported in Saudi Arabia ${ }^{21}$.

Genes related to chromatin modification, neural tube development, cardiac development, and protein phosphorylation were significantly over represented in the CHD cohort. A protein-protein interaction map for potentially significant CHD genes with connections 
greater than would be expected due to chance alone was produced (see Supplementary Figure 4 in Sifrim et al. ${ }^{16}$ ), and this includes known CHD genes such as NOTCH1, SOS1, SMAD4, and EP3OO. Such interaction maps will help to focus future CHD functional studies.

While these studies represent exciting steps forward in our understanding of CHD genetics, there was little overlap of the novel genes identified and already known genes, emphasizing that there is a long way to go to discover all the genes involved in CHD. However, previous analyses restricted to specific CHD phenotypes (Tetralogy of Fallot) have demonstrated an overlap with genes with known cardiac roles in the sarcomere and neural crest, for example ${ }^{22}$.

These studies already facilitate improvement to patient care. Multiple definitely pathogenic mutations in already established CHD genes have been identified, and these results are being fed back to the participants. Whilst a genetic diagnosis won't necessarily alter the medical or surgical management of their heart defect, it may lead to recommendations of other medical checks or longerterm screening to identify other potential problems, including cardiomyopathy ${ }^{6}$. It could also have implications for the wider family, who may be offered echocardiographic or genetic screening. Prenatal diagnosis with sonography, genetic testing, and the possibility of pre-implantation genetic diagnosis are all available, and couples may choose different options based on the risk of a foetus being affected. Hopefully, in the future, non-invasive prenatal diagnosis will also be possible. Parents often report that a genetic diagnosis is helpful, partly because having an explanation was beneficial and because many worried that they did something in the pregnancy to cause the heart problem.

These studies also help us learn about novel and already established genes. It appears that there is a recognisable phenotype for $C D K 13$ mutations that clinicians can look for when reviewing patients. The smaller numbers with $C H D 4$ and PRKD1 mutations mean that the phenotype is yet to be established, although there are some consistent and distinct features, particularly for $C H D 4^{23}$. Follow up of these individuals and identification of others who are affected will help us understand the phenotypic spectrum more fully. These studies have also expanded the phenotype of some well-known genes. For example, Zaidi et al. ${ }^{8}$ reported an individual with a $C H D 7$ mutation with none of the significant features of CHARGE syndrome. Targeted testing based on an individual's phenotype has created ascertainment bias in the past, and it is likely that the true range of phenotypes of even well-established CHD genes is not yet known. It is obvious that closer interaction between clinicians and researchers will be required in the future. An absence of mutations in genes with an established role in heart development, such as $N K X 2.5$, was apparent in the data set examined by Sifrim et al. ${ }^{12}$. This may reflect a truer incidence of the contribution of these genes to CHD rather than the previously published targeted sequencing studies. Even within the developmental disorders cohorts, there are mutations in genes such as CDK13 and CHD4 in individuals with and without CHD. Similarly, families with CHD often show nonpenetrance or mutation carriers without a severe phenotype, highlighting the importance of detailed phenotyping but also pointing towards modifying factors. Thus, an approach focusing on severely affected individuals would allow the identification of currently unknown genes and open up future perspectives to study genotype-phenotype correlation in more detail in selected mutation carriers as well as mouse models.

Clearly, there are huge benefits to using WES and other nontargeted testing in large cohorts, but the possibility of incidental findings requires careful consideration. Variants detected in genes unrelated to the primary study objectives may have significant clinical consequences for the individual: for example, the detection of a $B R C A$ gene mutation in a patient from a CHD cohort. There is some disagreement as to which incidental findings should be reported to the individuals concerned ${ }^{24,25}$ (see https:// www.mrc.ac.uk/documents/pdf/mrc-wellcome-trust-frameworkon-the-feedback-of-health-related-findings-in-researchpdf/ and https://www.genomicsengland.co.uk/wp-content/uploads/2015/03/ GenomicEnglandProtocol_030315_v8.pdf). In addition, there are obvious difficulties interpreting variants of uncertain significance and other issues such as carrier status. These matters need to be carefully considered and included within the consent process.

We now know that much larger cohorts of individuals with CHD must be examined to discover the remaining CHD-causing genes. This will require collaboration between different research groups and extensive data sharing, which may provide challenges for data protection and participant confidentiality. Consent for genetic testing is already particularly complicated in terms of feedback, variant interpretation, and incidental findings, policies on which are still evolving but clearly need to be evidence-based. The privacy of a person's data is obviously important, and the requirements to keep research data confidential have recently been highlighted by the PACE trial ${ }^{26}$. Despite participants not consenting to release anonymised data, the courts forced data release in response to a freedom of information request because of a strong public interest. This was despite the researchers' concerns that patients could potentially be identified. Open data and transparent research must be encouraged, but researchers might choose not to include data release as part of their consent process owing to concerns that it may put people off involvement in research. Funding agencies are playing an important role in driving data sharing, but more is needed from clinical diagnostic testing in addition to research cohorts.

The field of CHD genomics is rapidly changing, and there are many challenges facing researchers in this area. However, genomics research in CHD has the potential to immediately improve patient care by increasing the breadth of genetic testing for patients, clinical recognition of new syndromes, and tailored healthcare with better reproductive counselling and choices. This diverse population of individuals is increasing in numbers, and increased collaboration between researchers and clinicians is needed. Specifically, closer relationships among cardiologists, clinical geneticists, and researchers as well as genomic education for clinicians have been recommended ${ }^{27,28}$. Data sharing will be essential but must be done with careful consideration of participant confidentiality. Looking forwards, this is the dawn of a new era where 
the application of genomics can provide us with vital insights into the pathogenesis of disease and will help to transform patient care.

\section{Abbreviations}

CHD, congenital heart disease; DD, developmental disability; HHE, high heart expression; NS-CHD, non-syndromic congenital heart disease; PTV, protein-truncating variant; S-CHD, syndromic congenital heart disease; WES, whole exome sequencing.

\section{Competing interests}

The authors declare that they have no competing interests.
Grant information

JDB and AW are supported by the British Heart Foundation. $\mathrm{AS}, \mathrm{MH}$ and $\mathrm{M}-\mathrm{PH}$ are supported by the Wellcome Trust.

The funders had no role in study design, data collection and analysis, decision to publish, or preparation of the manuscript.

\section{Acknowledgements}

JDB and AW are supported by the British Heart Foundation. AS, MH and M-PH are supported by the Wellcome Trust. With thanks to the Brook Laboratory members, our collaborators, and the families that took part in our research.
1. F Marelli AJ, Mackie AS, lonescu-Ittu R, et al.: Congenital heart disease in the general population: changing prevalence and age distribution. Circulation. 2007; 115(2): 163-72.

PubMed Abstract | Publisher Full Text | F1000 Recommendation

2. Khairy $\mathrm{P}$, lonescu-Ittu $\mathrm{R}$, Mackie $\mathrm{AS}$, et al:: Changing mortality in congenita heart disease. J Am Coll Cardiol. 2010; 56(14): 1149-57.

PubMed Abstract | Publisher Full Text

3. F Marelli AJ, lonescu-Ittu R, Mackie AS, et al:: Lifetime prevalence of congenital heart disease in the general population from 2000 to 2010 Circulation. 2014; 130(9): 749-56.

PubMed Abstract | Publisher Full Text | F1000 Recommendation

4. $\quad \mathrm{F}$ Tutarel O, Kempny A, Alonso-Gonzalez R, et al:: Congenital heart disease beyond the age of 60: emergence of a new population with high resource utilization, high morbidity, and high mortality. Eur Heart J. 2014; 35(11): 725-32. PubMed Abstract | Publisher Full Text | F1000 Recommendation

5. F Andersen TA, Troelsen Kde L, Larsen LA: Of mice and men: molecular genetics of congenital heart disease. Cell Mol Life Sci. 2014; 71(8): 1327-52. PubMed Abstract | Publisher Full Text | Free Full Text | F1000 Recommendation

6. F Goldenberg PC, Adler BJ, Parrott A, et al:: High burden of genetic conditions diagnosed in a cardiac neurodevelopmental clinic. Cardiol Young. 2017; 27(3): 459-466.

PubMed Abstract | Publisher Full Text | F1000 Recommendation

7. $\mathrm{F}$ Ahrens-Nicklas RC, Khan S, Garbarini J, et al:: Utility of genetic evaluation in infants with congenital heart defects admitted to the cardiac intensive care unit. Am J Med Genet A. 2016; 170(12): 3090-7.

PubMed Abstract | Publisher Full Text | F1000 Recommendation

8. F Zaidi S, Choi M, Wakimoto $\mathrm{H}$, et al.: De novo mutations in histone-modifying genes in congenital heart disease. Nature. 2013; 498(7453): 220-3. PubMed Abstract | Publisher Full Text | Free Full Text | F1000 Recommendation

9. $\mathrm{F}$ Park E, Kim Y, Ryu H, et al.: Epigenetic mechanisms of Rubinstein-Taybi syndrome. Neuromolecular Med. 2014; 16(1): 16-24. PubMed Abstract | Publisher Full Text | Free Full Text | F1000 Recommendation

10. Nomura M, Li E: Smad2 role in mesoderm formation, left-right patterning and craniofacial development. Nature. 1998; 393(6687): 786-90. PubMed Abstract | Publisher Full Text

11. F Homsy J, Zaidi S, Shen $\mathrm{Y}$, et al:: De novo mutations in congenital heart disease with neurodevelopmental and other congenital anomalies. Science. 2015; 350(6265): 1262-6.

PubMed Abstract | Publisher Full Text | Free Full Text | F1000 Recommendation

12. Glessner JT, Bick AG, Ito K, et al:: Increased frequency of De novo copy number variants in congenital heart disease by integrative analysis of single nucleotide polymorphism array and exome sequence data. Circ Res. 2014; 115(10): 884-96.

PubMed Abstract | Publisher Full Text | Free Full Text

13. Gallagher TL, Arribere JA, Geurts PA, et al:: Rbfox-regulated alternative splicing is critical for zebrafish cardiac and skeletal muscle functions. Dev Biol. 2011; 359(2): 251-61.

PubMed Abstract | Publisher Full Text | Free Full Text

14. Yeo GW, Coufal NG, Liang TY, et al:: An RNA code for the FOX2 splicing regulator revealed by mapping RNA-protein interactions in stem cells. Nat Struct Mol Biol. 2009; 16(2): 130-7.

PubMed Abstract | Publisher Full Text | Free Full Text

15. Hickey EJ, Caldarone CA, McCrindle BW: Left ventricular hypoplasia: a spectrum of disease involving the left ventricular outflow tract, aortic valve, and aorta. J Am Coll Cardiol. 2012; 59(1 Suppl): S43-54. PubMed Abstract | Publisher Full Text

16. Sifrim A, Hitz MP, Wilsdon A, et al.: Distinct genetic architectures for syndromic and nonsyndromic congenital heart defects identified by exome sequencing Nat Genet. 2016; 48(9): 1060-5.

PubMed Abstract | Publisher Full Text

17. Liang K, Gao X, Gilmore JM, et al:: Characterization of human cyclindependent kinase 12 (CDK12) and CDK13 complexes in C-terminal domain phosphorylation, gene transcription, and RNA processing. Mol Cell Biol. 2015 35(6): 928-38.

PubMed Abstract | Publisher Full Text | Free Full Text

18. Blazek D, Kohoutek J, Bartholomeeusen K, et al:: The Cyclin K/Cdk12 complex maintains genomic stability via regulation of expression of DNA damage response genes. Genes Dev. 2011; 25(20): 2158-72. PubMed Abstract | Publisher Full Text | Free Full Text

19. Ingram KG, Curtis $C D$, Silasi-Mansat R, et al.: The NuRD chromatin-remodeling enzyme CHD4 promotes embryonic vascular integrity by transcriptionally regulating extracellular matrix proteolysis. PLoS Genet. 2013; 9(12): e1004031. PubMed Abstract | Publisher Full Text | Free Full Text

20. Fielitz J, Kim MS, Shelton JM, et al:: Requirement of protein kinase D1 for pathological cardiac remodeling. Proc Natl Acad Sci U S A. 2008; 105(8): 3059-63. PubMed Abstract | Publisher Full Text | Free Full Text

21. F Shaheen R, Al Hashem A, Alghamdi MH, et al:: Positional mapping of PRKD1, NRP1 and PRDM1 as novel candidate disease genes in truncus arteriosus. J Med Genet. 2015; 52(5): 322-9.

PubMed Abstract | Publisher Full Text | F1000 Recommendation

22. F Grunert M, Dorn C, Schueler M, et al:: Rare and private variations in neural crest, apoptosis and sarcomere genes define the polygenic background of isolated Tetralogy of Fallot. Hum Mol Genet. 2014; 23(12): 3115-28. PubMed Abstract | Publisher Full Text | F1000 Recommendation

23. F Weiss K, Terhal PA, Cohen L, et al: De Novo Mutations in CHD4, an ATPDependent Chromatin Remodeler Gene, Cause an Intellectual Disability Syndrome with Distinctive Dysmorphisms. Am J Hum Genet. 2016; 99(4): $934-41$.

PubMed Abstract | Publisher Full Text | Free Full Text | F1000 Recommendation

24. Wolf SM, Lawrenz FP, Nelson CA, et al:: Managing incidental findings in human subjects research: analysis and recommendations. J Law Med Ethics. 2008; 36(2): 219-48, 211

PubMed Abstract | Publisher Full Text | Free Full Text

25. Green RC, Berg JS, Grody WW, et al:: ACMG recommendations for reporting of incidental findings in clinical exome and genome sequencing. Genet Med. 2013; 15(7): 565-74. PubMed Abstract | Publisher Full Text | Free Full Text

26. White PD, Goldsmith KA, Johnson AL, et al:: Comparison of adaptive pacing therapy, cognitive behaviour therapy, graded exercise therapy, and specialist medical care for chronic fatigue syndrome (PACE): a randomised trial. Lancet. 2011; 377(9768): 823-36.

PubMed Abstract | Publisher Full Text | Free Full Text

27. F Mital S, Musunuru K, Garg V, et al.: Enhancing Literacy in Cardiovascular Genetics: A Scientific Statement From the American Heart Association. Circ Cardiovasc Genet. 2016; 9(5): 448-67. PubMed Abstract | Publisher Full Text | F1000 Recommendation

28. F Landis BJ, Ware SM: The Current Landscape of Genetic Testing in Cardiovascular Malformations: Opportunities and Challenges. Front Cardiovasc Med. 2016; 3: 22.

PubMed Abstract | Publisher Full Text | Free Full Text | F1000 Recommendation 


\section{Open Peer Review}

\section{Current Peer Review Status:}

\section{Editorial Note on the Review Process}

Faculty Reviews are review articles written by the prestigious Members of Faculty Opinions. The articles are commissioned and peer reviewed before publication to ensure that the final, published version is comprehensive and accessible. The reviewers who approved the final version are listed with their names and affiliations.

\section{The reviewers who approved this article are:}

\section{Version 1}

\section{Maria Grazia Andreassi}

Institute of Clinical Physiology, Italian National Research Council (CNR), Pisa, Italy

Competing Interests: No competing interests were disclosed.

\section{Silke R. Sperling}

Cardiovascular Genetics, Experimental and Clinical Research Center, Charité-Universitätsmedizin Berlin, Berlin, Germany

Competing Interests: No competing interests were disclosed.

The benefits of publishing with F1000Research:

- Your article is published within days, with no editorial bias

- You can publish traditional articles, null/negative results, case reports, data notes and more

- The peer review process is transparent and collaborative

- Your article is indexed in PubMed after passing peer review

- Dedicated customer support at every stage

For pre-submission enquiries, contact research@f1000.com 